\title{
Diabetes and the human condition
}

\section{Adapting to a global dilemma}

T he treatment of diabetes before insulin therapy tested the skills of the clinician and the commitment of the patient. But by the 1920s, insulin became widely available for the diabetic community in North America. ${ }^{1}$

If diabetes was once considered a simple problem of insulin deficiency it is not seen that way now. Instead it is a window on complex metabolic distortions, signals, substrates and reactions.

\section{A second form of diabetes}

An extraordinary twist in the diabetes story has been the epidemic of type 2 diabetes. Rapid changes in the human environment - massive migrations from rural to urban environments with upheavals in diet away from traditional foods - have accompanied soaring prevalence rates in developed and developing economies alike.

Why cannot humans adapt to our new environments? Maybe we can - but it will take ages. Plutella xylostella caterpillars adapt to an obesogenic environment, but in eight generations. ${ }^{2}$ So we must turn instead to the environmental factors that promote diabetes and hinder its treatment.
What we eat is inextricably linked to the food that is available, affordable and acceptable. In order to make lasting and sustainable changes to the food environment, the food system from paddock to plate must change. This may occur through the accumulation of many small changes.

\section{The role of Big Farmer}

Agricultural subsidies for cash crops can be a health hazard. Subsidised corn and soybean oil in the United States lead to cheap ultraprocessed foods. Production of high-fructose corn syrup, used in beverages, is supported by large government subsidies.

But with reduced subsidies corn farmers are now planting orchards and growing vegetables. Cause and effect cannot be disentangled, but changes in agriculture are occurring in parallel with health awareness. ${ }^{3}$ Farm incomes are recovering in parallel with increased sales of fruits and vegetables.

Improvements must be made not only in food production, but also in food-processing practices. Product reformulation can reduce the levels of salt and sugar and replace trans and saturated fats. Ensuring that a health-promoting
Stephen R Leeder

MD, PhD, FRACP

Editor-in-Chief ${ }^{1}$

Shauna M Downs

Postgraduate Associate ${ }^{2}$

1 Medical Journal of Australia, Sydney, NSW.

2 Menzies Centre for Health Policy, University of Sydney, Sydney, NSW.

sleeder@mja.com.au

doi: 10.5694/mjal4.00943 
replacement is available depends on upstream agricultural production and policies.

Again in the US, where consumer awareness of the hazards of trans fats has grown rapidly, the food production industry has responded. In 2005, the Dow Chemical Company launched canola and sunflower seeds for cooking oils with a longer shelf life and suitable for frying. This shift occurred in parallel with the requirement for all foods to be labelled with trans fat content. ${ }^{4}$

Food product reformulation followed, and 600 million tons of trans and saturated fats were removed from the US diet between 2005 and 2012. ${ }^{4}$

So with a blend of informed consumer pressure, legislative support and innovative food industry responsiveness, changes do occur.

In addition to the toxic food environment, many new cities and neighbourhoods are not conducive to walking. Instead, sitting sullen and stressed in traffic jams is normative. Much as with the food environment, promising changes upstream in urban design can be both healthpromoting and attractive to developers. More safe bicycle lanes, aesthetic rather than cracked and lumpy footpaths, and accessible public transportation systems increase physical activity levels. ${ }^{5,6}$

\section{Equity of access to care}

Alongside these preventive changes for type 2 diabetes, the environment that limits care for patients with diabetes must change. Each year, thousands of children with type 1 diabetes die in less economically advanced societies for lack of insulin. ${ }^{7,8}$ Families face the shocking choice between insulin for one child and food for the others. ${ }^{7}$

We do not know everything about diabetes and the environment but we know enough to advocate for change - at all points in the agri-food chain, in the way we design our cities and in seeking justice for all people who need them to have access to lifesaving diabetes therapies.

\section{Competing interests: $N$ o relevant disclosures.}

Provenance: Not commissioned; not externally peer reviewed.

1 Leeder SR. The history of insulin: the mystery of diabetes. Med J Aust 2013; 199: 227.

2 Warbrick-Smith J, Behmer ST, Lee KP, et al. Evolving resistance to obesity in an insect. Proc Natl Acad Sci 2006; 103: 14045-14049.

3 Moss M. The seeds of a new generation. New York Times 2014; 4 Feb. http:// www.nytimes.com/2014/02/05/dining/the-seeds-of-a-new-generation. html (accessed Feb 2014).

4 Pfitzer M, Bockstette V, Stamp M. Innovating for shared value. Harvard Business Rev 2013; Sep. http://hbr.org/2013/09/innovating-for-sharedvalue/ar/l (accessed Feb 2014).

5 Sallis JF, Floyd MF, Rodríguez DA, Saelens BE. Role of built environments in physical activity, obesity, and cardiovascular disease. Circulation 2012; 125: 729-737.

6 Yang Y, Diez-Roux AV. Walking distance by trip purpose and population subgroups. Am J Prev Med 2012; 43: 11-19.

7 Gale EAM. Dying of diabetes. Lancet 2006; 368: 1626-1628.

8 Beran D, McCabe A, Yudkin JS. Access to medicines versus access to treatment: the case of type 1 diabetes. Bull World Health Organ 2008; 86: 648-649. 